\title{
COMPARING EXPECTATIONS TO EXPERIENCE IN ONLINE TEACHING
}

\author{
McCahan S; Cohen S; Karney B \\ Faculty of Applied Science \& Engineering, Ontario Canada \\ mccahan@mie.utoronto.ca; sh.cohen@utoronto.ca; karney@ecf.utoronto.ca
}

\section{INTRODUCTION}

The Faculty of Applied Science and Engineering at the University of Toronto has undertaken a variety of online teaching projects over the past year. Our Instructional Technology Office has supported the development and delivery of a MOOC (massive open online course) delivered on the EdX platform; the development and delivery of two first year engineering calculus courses; and several projects aimed at developing reusable digital learning objects (usually referred to as RLO's or DLO's). The development of DLO's is leading to an increasing use of inverted classroom teaching, and other non-traditional approaches.

We generally select highly experienced instructors who have been successful in their teaching for these types of projects. Prior to launching into their respective projects, the instructors involved in these projects received training and support based on the current understanding of best practices in the delivery of online learning. This included attending programs such as the University of Toronto Course Design Institute which has a significant component dedicated to the design of online learning experiences. The instructors also regularly consulted with the Director of Online Strategy for the University and worked closely with personnel in the Instructional Technology Office.

While this preparation was certainly helpful, it did not fully prepare the instructors for the differences between in-person and on-line teaching. This paper discusses two projects in particular: a MOOC called "Our Energetic Earth" which was delivered in the fall of 2013; and a set of two first year engineering calculus courses that were available to our students for credit during the 2013/14 academic year.

\section{MOOC PROJECT}

In the Fall of 2013 we developed and delivered our first Massive Open Online Course (MOOC). A MOOC is free to anyone in the world who wants to sign up, there is no enrolment limit, and we do not grant credit for the course. If a participant completes the course they get a certificate of completion. The "Our Energetic Earth" MOOC took about 6 months to prepare and was delivered over a 6 week period. The instructor (B. Karney) was supported by two teaching assistants and the Instructional Technology Office. The course had 10,857 registrants of whom 458 completed the course for the certificate. Interestingly there were 1789 people who completed the week 6 quiz, but most of these participants did not complete enough other work to earn the certificate. Also 2827 new people have viewed the course materials in the time since the course was ended (people who were not originally registered for the course). This is typical of a MOOC and suggests people are engaging with the material beyond a traditional course paradigm.

Since the "recognition value" of the certificate was low (in our view) we thought the majority of people participating would be interested in learning and not so interested in the evaluation through certificate and quizzes. However, we were surprised at how many of the complaints were about the quizzes being too hard. Surprisingly, a number of students were doing the quizzes within an hour of the week's material being posted. In other words, they were quite ready to challenge the quiz before the learning exercises, which might at least partly explain why they found the quizzes challenging.

We were disappointed to what extent "evaluation" played a big role in people's minds, although this may have been the vocal minority rather than the silent majority. Our initial impression was that people would be engaging in a MOOC purely for the learning outcomes. Though in retrospect we might have expected evaluation would be highly valued given the emphasis this has in most educational systems. It is interesting to note that research at UofT and elsewhere suggests that 80 to $85 \%$ of MOOC participants have an undergraduate degree [1], suggesting that the majority of participants have been successful learners in higher education where assessment is usually the key indicator of success.

The videos for this project were 15 to 20 minutes in length. Some people loved the videos but fewer people watched the videos than did the quizzes, so that was a surprise and a bit of disappointment. Again, it appeared that there was more interest in completing the evaluation than engaging in the material.
The other surprise came from our own students some of whom were encouraged to do the MOOC alongside the in-person version of the course. One of our hopes for the course is that we could encourage more direct experimentation and observation of the world and that partly happened. Many participants seemed to enjoy sharing their pictures of environmental phenomena and other interactive aspects of the course. However there was push-back in the local student group, a number of whom identified that the thing that could best be dropped was the handson component! This did not support the spirit of science nor the spirit of exploration we were hoping to instill, at least for a subset of the total group.

Our key motivations for engaging in this project was the opportunity to create high quality learning materials that we can reuse to enrich the learning experience for our students; and the opportunity to engage a broader community of learners with our students in the learning process. Both of these aspects of the MOOC were at least partly realized. In the future we are going to be utilizing the materials developed for the MOOC in our courses more broadly. The experience of learning in an open environment holds a fascinating potential for enhancing the experience for our students.

\section{SCOC PROJECT}

At the same time as we were developing the MOOC, we were also developing two small closed online courses (SCOC's) which are accessible only to our own students and are taken for credit. The courses are alternatives to the traditional calculus courses required for most first year engineering students. The preparation for these courses took approximately 6 months and included development of videos, assessments, and an online interaction strategy. The instructor (S. Cohen) was supported by one teaching assistant and the Instructional Technology Office. Approximately 500 videos were produced in total for the two courses. Some are very short, but on average these run about 7 to 10 minutes each. The videos include typical "lectures" on concepts, example problem solving, and videos "on location" showing applications of math and mathematical thinking. The "on location" videos showing the application of engineering math to architecture, or a kinesiology lab were especially popular. To enhance interaction, a Piazza discussion board was used.

We actually found very little difference between the expectations and the result. We knew that this project will require a lot of work. It certainly did. We expected that it would attract a reasonably small number of students and that the course would not match everyone's expectations. That seemed to be the case. One of the primary reasons students gave for choosing not to enroll in the online section was that they prefer to be in class with their friends.

The only thing that the instructor found odd was his reaction to the camera. He adapted to the styles of three different types of videos mini-lectures, examples, and long demonstrations - very quickly and found that it was easy to find opportunities where these provided freedom he did not have in a traditional class. On the other hand, he still fumbled greatly with anything formal - completely pre-scripted videos were the most difficult.

The greatest difficulties with teaching online were the lack of immediacy and (related to this) the lack of humour. Although he had no problems doing the lectures, he found himself wishing for some calland-response. The lectures often felt quite dry without the brief, light interaction he was used to with the class. However a number of students commented positively on the humour they found in the lecture videos.

In summary, both projects have produced high quality DLO's that we will be using in traditional, blended, or inverted teaching in the future. However, the experience of teaching in these ways is different and presents a wide variety of both challenges and opportunities.

\section{REFERENCES}

1. Christensen G, Steinmetz A, Alcorn B, Bennett A, Woods D, and Emanuel EJ, « The MOOC Phenomenon : Who Takes Massive Open Online Courses and Why ? ", (November 6, 2013). Available at SSRN: http://ssrn.com/abstract=2350964. 